\title{
Piceatannol Inhibits Melanogenesis by Its Antioxidative Actions
}

\author{
Takako YoKOZAWA ${ }^{a}$ and You Jung $\mathrm{KIM}^{*, a, b}$ \\ ${ }^{a}$ Institute of Natural Medicine, University of Toyama; 2630 Sugitani, Toyama 930-0194, Japan: and ${ }^{b}$ Department of \\ Dental Hygiene, Busan Women's College; Busanjin-Gu, Busan 617-734, Korea. \\ Received April 6, 2007; accepted August 20, 2007; published online August 21, 2007
}

\begin{abstract}
In our efforts to find new skin lightening agents, piceatannol (PICE) was investigated for its antioxidative property and ability to inhibit melanogenesis. In this study, PICE's effect on inhibition of mushroom tyrosinase, and tyrosinase inhibiting activity and melanin content were assessed utilizing the B16F10 melanoma cell (B16 cell) culture system. Results indicated that PICE has a strong antityrosinase activity $\left(\mathrm{IC}_{50}=1.53 \mu \mathrm{M}\right)$. To evaluate the relative efficacy of PICE compared to other tyrosinase inhibitors, its inhibitory effect was compared and showed that PICE was significantly stronger than kojic acid $\left(\mathrm{IC}_{50}=50.1 \mu \mathrm{M}\right)$ and resveratrol $\left(\mathrm{IC}_{50}=63.2 \mu \mathrm{M}\right)$. Furthermore, PICE was shown to down-regulate melanin content. To document PICE's antioxidative property, which is known to influence melanogenic activity, we assessed reactive species (RS) generation, reduced glutathione (GSH) and oxidized glutathione (GSSG) levels in these B16 cells. The results showed that PICE suppressed RS generation and enhanced the GSH/GSSG ratio. In conclusion, our results indicated that the antimelanogenic action of PICE is likely exhibited by the combined effect of PICE's antioxidative property and its ability to suppress RS generation while increasing the GSH/GSSG ratio.
\end{abstract}

Key words piceatannol; melanogenesis; tyrosinase; antioxidative property; reduced glutathione/oxidized glutathione ratio

Melanin is the pigment giving characteristic color to the skin and hair, and is synthesized in melanosomes transferred from melanocytes. Although melanin plays an important protective role against UV light, over production and accumulation of melanin pigment it could create serious skin problems such as freckles, age spots, and melasma. ${ }^{1)}$ Thus, the inhibition of melanogenesis has been the focus of medicinal and cosmetic treatments for skin depigmenting and lightening.

Melanogenesis that is regulated by the key enzyme, tyrosinase, is also affected by other non-enzymatic factors such as ultraviolet rays and $\alpha$-melanocyte-stimulating hormone $\left(\alpha\right.$-MSH). ${ }^{2)}$ Tyrosinase (monophenol monooxygenase, EC 1.14.18.1), also known as polyphenol oxidase is an enzyme that catalyzes the oxidation of monohydric phenols (e.g. such as tyrosine). ${ }^{3)}$ During melanogenesis, if free radicals are improperly processed, hydrogen peroxide is produced, causing production of more damaging hydroxyl radicals and other reactive oxygen species. ${ }^{4}$ )

It has been reported that antioxidants or compounds with redox properties can inhibit or delay hyperpigmentation, ${ }^{5)}$ and that reduced glutathione (GSH), an important biological reductant, is involved in regulation of melanin synthesis. ${ }^{6}$ Our recent study characterized the antimelanogenic action of $4,4^{\prime}$-dihydroxybiphenyl, which is likely carried out by a combined effect of its antioxidative property and ability to increase intracellular GSH levels. ${ }^{7)}$

In the past, many depigmenting substances, including phenolic compounds ${ }^{8-10)}$ and stilbene derivatives, ${ }^{11,12)}$ have been reported to have skin whitening effects. Piceatannol (PICE; 3,5,3', $4^{\prime}$-tetrahydroxy-trans-stilbene) and resveratrol (RES; trans-3,5,4'-tridydroxystilbene) are phenolic compounds that occur naturally in grapes and red wine. ${ }^{13)}$ RES is known to have antioxidative, estrogenic, and anti-cancer properties. ${ }^{14)}$ Its natural metabolite, the RES analogue, piceatannal (PICE) is reported to possess antioxidative, anti-tumorigenic, and apoptosis-inducing effects. ${ }^{15)}$ However, PICE's inhibitory effect on melanogenesis has not been reported to date. This study compares the inhibitory effect between PICE and RES against melanogenesis. The effect of PICE on the inhibition of mushroom tyrosinase was evaluated. Additionally, tyrosinase inhibiting activity and melanin content were assessed in B16F10 melanoma cells (B16 cells).

To elucidate the underlying process by which PICE inhibits tyrosinase activity and melanogenesis, PICE's effect on reactive species (RS) generation and GSH and oxidized glutathione (GSSG) ratio were assessed.

\section{MATERIALS AND METHODS}

Materials PICE, RES, $\alpha$-MSH, and all other chemical reagents were purchased from Sigma Chemical Co. (St. Louis, MO, U.S.A.).

Cell Culture B16 cells were purchased from Korean Cell Line Bank (Seoul, Korea) were cultured in DMEM with $10 \%$ fetal bovine serum (FBS; Gibco, NY, U.S.A.) and penicillin/streptomycin $(100 \mathrm{IU} / 50 \mu \mathrm{g} / \mathrm{ml})$ in a humidified atmosphere containing $5 \% \mathrm{CO}_{2}$ in air at $37^{\circ} \mathrm{C}$. B16 cells were cultured in 24-well plates for each assay. All the experiments were performed in triplicate and repeated three times to ensure reproducibility.

Studies on the Inhibitory Effect of PICE and RES on Tyrosinase Activity. a) Mushroom Tyrosinase Activity To estimate the inhibitory action of PICE and RES on tyrosinase, tyrosinase isolated from mushroom was utilized as described previously with a minor modification. ${ }^{16)}$ Briefly, $20 \mu \mathrm{l}$ of aqueous solution of mushroom tyrosinase (1000 units) was added to a 96-well microplate, in a total volume of $200 \mu \mathrm{l}$ assay mixture containing $1 \mathrm{~mm}$ L-tyrosine solution,<smiles>Oc1cc(O)cc(C=Cc2ccc(O)c(O)c2)c1</smiles>

PICE<smiles>Oc1ccc(/C=C/c2cc(O)cc(O)c2)cc1</smiles>

RES
Fig. 1. Chemical Structures of PICE and RES 
$50 \mathrm{~mm}$ phosphate buffer (pH 6.5). The assay mixture was incubated at $25^{\circ} \mathrm{C}$ for $30 \mathrm{~min}$. Following incubation, the amount of dopachrome produced in the reaction mixture was determined spectrophotometrically at $492 \mathrm{~nm}$ in a microplate reader. $\mathrm{IC}_{50}$ is the concentration of a drug that inhibits a standard response by $50 \%$. The $\mathrm{IC}_{50}$ is a value derived from the $X$-axis. It is determined from the alignment of the dose response curve on the dependent $Y$-axis. In the current study, to determine the $\mathrm{IC}_{50}$ of a drug, dose-dependent inhibition experiments were performed in triplicate. We determined the log-linear curves and their equations based on the inhibition percentages at three doses for each experiment. Then, we calculated individual $\mathrm{IC}_{50}$ when $Y$-axis showed $50 \%$ of the inhibition percentage.

b) Murine Tyrosinase Activity Tyrosinase activity in B16 cells was assessed by measuring the rate of oxidation of L-3,4-dihydroxyphenylalanine (L-DOPA). ${ }^{16)}$ Cells were plated in 24-well dishes at a density of $5 \times 10^{4}$ cells $/ \mathrm{ml}$. B16 cells were incubated in the presence or absence of $100 \mathrm{~nm} \alpha$-MSH and then treated for $24 \mathrm{~h}$ at various concentrations of PICE and RES. The cells were lysed in $100 \mu \mathrm{l}$ of $50 \mathrm{~mm}$ sodium phosphate buffer ( $\mathrm{pH}$ 6.8) containing $1 \%$ Triton X-100 and $0.1 \mathrm{~mm}$ phenylmethylsulfonyl fluoride and then frozen at $-80^{\circ} \mathrm{C}$ for $30 \mathrm{~min}$. After thawing and mixing, cellular extracts were clarified by centrifugation at $12000 \times \boldsymbol{g}$ for $30 \mathrm{~min}$ at $4{ }^{\circ} \mathrm{C}$. The supernatant $(80 \mu \mathrm{l})$ and $20 \mu \mathrm{l}$ of L-DOPA $(2 \mathrm{mg} / \mathrm{ml})$ were placed in a 96-well plate, and the absorbance at $492 \mathrm{~nm}$ was read every $10 \mathrm{~min}$ for $1 \mathrm{~h}$ at $37^{\circ} \mathrm{C}$ using an ELISA plate reader.

Evaluation of Melanogenesis in B16 Cells Determination of melanin content was performed using a modified method of Bilodeau et al. ${ }^{17)}$ In brief, B16 cells $\left(5 \times 10^{4}\right)$ were plated on 24-well multi-dishes and incubated in the presence or absence of $100 \mathrm{~nm} \alpha$-MSH. Cells were then incubated for $24 \mathrm{~h}$ with or without PICE at concentrations ranging from 5 to $100 \mu \mathrm{M}$. After washing twice with phosphate buffered saline, samples were dissolved in $100 \mu$ l of $1 \mathrm{~N} \mathrm{NaOH}$. The samples were incubated at $60^{\circ} \mathrm{C}$ for $1 \mathrm{~h}$ and mixed to solubilize the melanin. Absorbance at $405 \mathrm{~nm}$ was compared with a standard curve of synthetic melanin.

Cell Viability Assay The cell viability assay was performed by Tada et al.'s method ${ }^{18)}$ using 3-(4,5-dimethylthiazol-2-yl)-2,5-diphenyltetrazolium bromide (MTT; Sigma Chemical Co., St. Louis, U.S.A.). In brief, $5 \times 10^{4}$ cells/well were plated in a 24-well plate. After cells were exposed to PICE at concentrations ranging from 5 to $400 \mu \mathrm{M}$ for $24 \mathrm{~h}$, MTT solutions were added and the insoluble derivative formed by cellular dehydrogenase was solubilized with EtOH-dimethyl sulfoxide (DMSO) (1:1 mixture solution); the absorbance of each well was read at $560 \mathrm{~nm}$ using a microplate reader.

Estimation of RS Generation in B16 Cells RS generation was estimated in culture supernatant. ${ }^{19)}$ Twenty-five millimolar 2',7'-dichlorofluorescein diacetate (DCFH-DA) was added to incubation media, and changes in fluorescence were evaluated at an excitation wavelength of $486 \mathrm{~nm}$ and emission wavelength of $530 \mathrm{~nm}$ for $30 \mathrm{~min}$.

Determination of GSH and GSSG Levels GSH and GSSG levels were assessed by the method of Pandey and Katiyar. ${ }^{20)}$ Twenty-five percent of the meta-phosphoric acidadded cell pellets were centrifuged at $12000 \times \boldsymbol{g}$ for $10 \mathrm{~min}$, and the supernatant was taken for the assessment. For GSH, $1 \mathrm{~mm}$ EDTA-50 mм phosphate buffer was added to the supernatant followed by $o$-phthaladehyde. After $20 \mathrm{~min}$ at room temperature, the fluorescence was determined at excitation wavelength of $360 \mathrm{~nm}$ and emission wavelength of $460 \mathrm{~nm}$. GSSG was estimated after preincubated with $N$-ethylmaleimide for $20 \mathrm{~min}$ and $0.1 \mathrm{M} \mathrm{NaOH}$ was replaced for $1 \mathrm{~mm}$ EDTA-50 mm phosphate buffer.

Protein Assay The concentration of protein was estimated by Bicinchoninic Acid protein assay. ${ }^{21)}$ All samples were assayed in triplicate.

Statistical Analysis Data were collected as mean \pm standard error $(n=5)$ and the biological significance $p<0.05$ was determined by the Student's $t$-test.

\section{RESULTS}

Table 1 reveals the results of the inhibition of mushroom tyrosinase activity by PICE, RES and kojic acid. Data show that the inhibitory potency of PICE on mushroom tyrosinase was dose-dependent. A low $\mathrm{IC}_{50}$ value $(1.53 \mu \mathrm{M})$ indicates that the potency was significantly higher than that of kojic acid $\left(\mathrm{IC}_{50}=50.1 \mu \mathrm{M}\right)$, which was used as a reference compound. In addition, PICE showed more potent efficacy than $\operatorname{RES}\left(\mathrm{IC}_{50}=63.2 \mu \mathrm{M}\right)$.

The Effect of PICE on Cell Viability The data on the cell viability assay using MTT for B16 cells are given in Fig. 2. At growth doses of 5, 100, 200, and $400 \mu \mathrm{M}$ of PICE, cell viability was $99.8,98.7,95.3$, and $90.1 \%$, respectively during a $24 \mathrm{~h}$ treatment. These data clearly showed the non-cytotoxic nature of PICE in B16 cells.

Inhibitory Action of Tyrosinase and Melanin Content of B16 Cells by PICE We investigated the inhibitory effect of PICE and RES on tyrosinase activity in B16 cells treated with $\alpha$-MSH (Fig. 3). After $24 \mathrm{~h}$ incubation with PICE, tyrosinase activities were suppressed, showing $141.6 \%$ at $5 \mu \mathrm{M}$,

Table 1. Effects of PICE, RES and Kojic Acid on Mushroom Tyrosinase Activity

\begin{tabular}{lc}
\hline \hline Compound & $\mathrm{IC}_{50}(\mu \mathrm{M})$ \\
\hline PICE & 1.53 \\
RES & 63.2 \\
Kojic acid & 50.1 \\
\hline
\end{tabular}

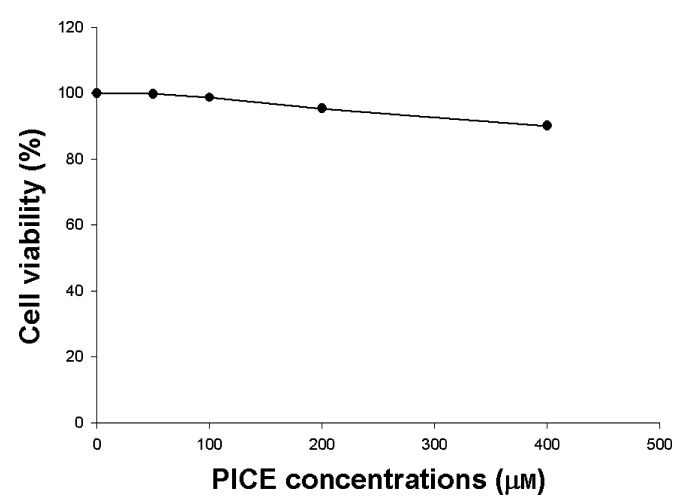

Fig. 2. The Effects of PICE on the Viability of B16 Cells

Cells were treated with various doses of PICE and RES $(50-400 \mu \mathrm{M})$ and were examined by MTT assay. Data are expressed as \% of cell viability. 


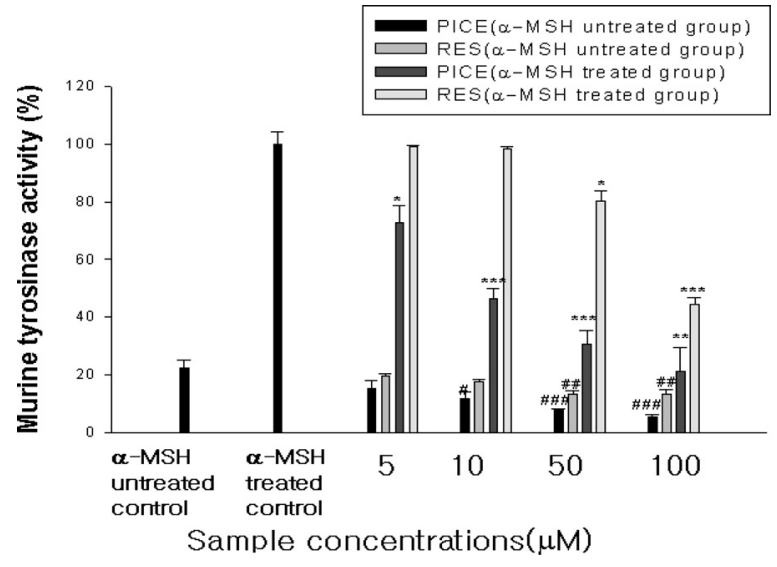

Fig. 3. Murine Tyrosinase Activity in B16 Cells after $24 \mathrm{~h}$ of Treatment with or without PICE and RES

Enzyme assay was performed as described in Materials and Methods. Results are expressed as percentages of control, and data are the mean \pm S.E.M. of at least three determinations. * Significantly different from the $\alpha$-MSH-treated control group $(* p<0.05$, $* * p<0.01, * * * p<0.001)$. \# Significantly different from the $\alpha$-MSH-untreated control

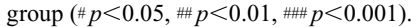

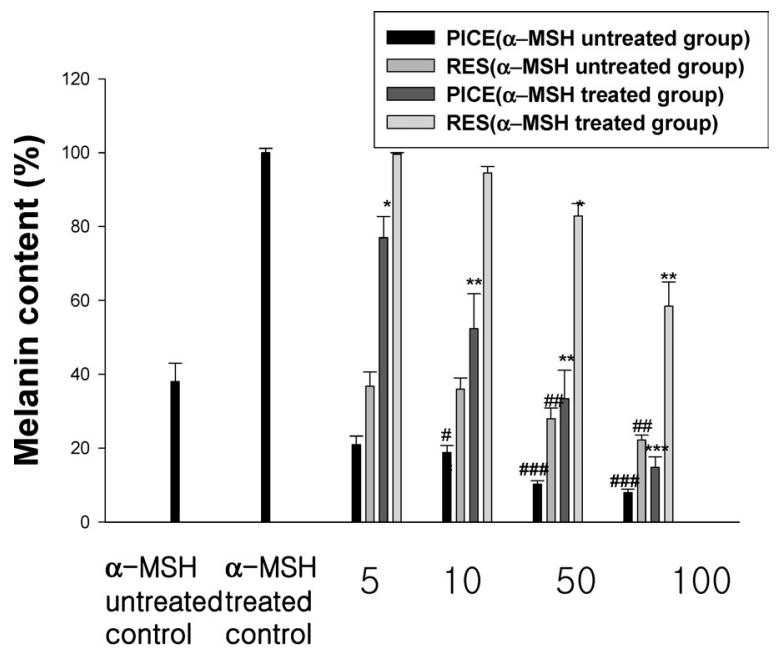

\section{Sample concentrations $(\mu \mathrm{M})$}

Fig. 4. Effects of PICE and RES on the Melanin Content

Melanin content assessments were performed as described in Materials and Methods. Results are expressed as percentages of control, and data are the mean \pm S.E.M. of at least three determinations. * Significantly different from the $\alpha$-MSH treated control group $(* p<0.05, * * p<0.01, * * * p<0.001)$. \# Significantly different from the $\alpha$-MSHuntreated control group ( $\# p<0.05$, \# $p<0.01$, \#\# $p<0.001$ ).

$90.37 \%$ at $10 \mu \mathrm{M}, 59.86 \%$ at $50 \mu \mathrm{M}$, and $41.17 \%$ at $100 \mu \mathrm{M}$ compared to the $\alpha$-MSH-treated control group (194.4\%). Further, RES was shown to inhibit tyrosinase activities, indicating $198.7 \%$ at $5 \mu \mathrm{M}, 196.0 \%$ at $10 \mu \mathrm{M}, 155.6 \%$ at $50 \mu \mathrm{M}$, and $86.63 \%$ at $100 \mu \mathrm{M}$. To gain evidence on the involvement of PICE and RES in melanogenesis, the inhibition of melanin production in B16 cells were examined. As exhibited in Fig. 4 , in cells treated with PICE and RES, the melanin content was decreased. PICE decreased melanin levels in a dose-dependent manner: $76.96 \%$ at $5 \mu \mathrm{M}, 52.34 \%$ at $10 \mu \mathrm{m}, 33.39 \%$ at $50 \mu \mathrm{m}$ and $14.80 \%$ at $100 \mu \mathrm{m}$ compared to the $\alpha-\mathrm{MSH}$ treated control group, whereas RES revealed $99.57 \%$ at $5 \mu \mathrm{M}$, $94.49 \%$ at $10 \mu \mathrm{M}, 82.88 \%$ at $50 \mu \mathrm{m}$ and $58.42 \%$ at $100 \mu \mathrm{M}$ also compared to the control group. The data on melanin content correlate well with the data on the inhibitory effect
Table 2. Effects of PICE, RES and Trolox on RS Generation

\begin{tabular}{lc}
\hline \hline Group & $\begin{array}{c}\text { RS generation } \\
\text { (fluorescence/min/mg protein) }\end{array}$ \\
\hline Control & $9.60 \pm 0.46$ \\
PICE $(5 \mu \mathrm{M})$ & $2.83 \pm 1.13^{* *}$ \\
PICE $(10 \mu \mathrm{M})$ & $1.77 \pm 1.03^{* *}$ \\
PICE $(50 \mu \mathrm{M})$ & $0.92 \pm 0.45^{* * *}$ \\
RES $(5 \mu \mathrm{M})$ & $8.92 \pm 0.97$ \\
RES $(10 \mu \mathrm{M})$ & $6.55 \pm 0.91^{*}$ \\
RES $(50 \mu \mathrm{M})$ & $5.10 \pm 0.33^{* *}$ \\
Trolox $(5 \mu \mathrm{M})$ & $8.87 \pm 0.22$ \\
Trolox $(10 \mu \mathrm{M})$ & $7.22 \pm 0.67$ \\
Trolox $(50 \mu \mathrm{M})$ & $6.02 \pm 0.75^{*}$ \\
\hline
\end{tabular}

Each value represents the mean \pm S.E.M. of three determinations. $*$ Statistically significant difference in comparison with the control group. $* p<0.05$, $* * p<0.01$, $* * * p<0.001)$.

Table 3. Effects of PICE and RES on GSH and GSSG Levels and Their Ratio

\begin{tabular}{llll}
\hline \hline Group & \multicolumn{2}{c}{ GSH } \\
& $(\mu \mathrm{mol} / \mathrm{mg}$ protein $)$ & $\begin{array}{c}\text { GSSG } \\
(\mu \mathrm{mol} / \mathrm{mg} \text { protein })\end{array}$ & GSH/GSSG \\
\hline Control & $7.11 \pm 0.98$ & $1.03 \pm 0.09$ & $6.90 \pm 1.50$ \\
PICE $(5 \mu \mathrm{M})$ & $31.3 \pm 7.59^{*}$ & $0.76 \pm 0.07^{*}$ & $41.1 \pm 12.3^{*}$ \\
PICE $(10 \mu \mathrm{M})$ & $60.1 \pm 8.88^{* *}$ & $0.49 \pm 0.03^{* *}$ & $121 \pm 20.6^{*}$ \\
PICE $(50 \mu \mathrm{M})$ & $83.4 \pm 10.4^{* * *}$ & $0.23 \pm 0.06^{* *}$ & $367 \pm 121^{*}$ \\
RES $(5 \mu \mathrm{M})$ & $7.29 \pm 0.93$ & $0.99 \pm 0.13$ & $7.32 \pm 1.10$ \\
$\operatorname{RES}(10 \mu \mathrm{M})$ & $7.91 \pm 0.04$ & $0.89 \pm 0.05^{*}$ & $8.89 \pm 0.10^{*}$ \\
$\operatorname{RES}(50 \mu \mathrm{M})$ & $10.2 \pm 0.39^{*}$ & $0.67 \pm 0.04$ & $15.1 \pm 0.41^{*}$
\end{tabular}

The cells were cultured to sub-confluence then incubated for $24 \mathrm{~h}$ in the presence of PICE and RES, then assayed for GSH and GSSG levels, as detailed in Materials and Methods. Each value represents the mean \pm S.E.M. of three determinations.* Statistically significant difference in comparison with control group. $(* p<0.05, * * p<0.01$, $* * * p<0.001)$.

on murine tyrosinase activity. The murine tyrosinase activity and melanin content were also down-regulated by PICE and RES as compared to $\alpha$-MSH untreated control, but the suppressive effects revealed stronger when treated with $\alpha$-MSH.

Down-Regulation of RS Generation The effects of PICE and RES on changes of RS are shown in Table 2. RS generation was significantly decreased by PICE to $33.33 \%$ at $5 \mu \mathrm{M}, 81.56 \%$ at $10 \mu \mathrm{M}$, and $90.42 \%$ at $50 \mu \mathrm{M}$ compared to the control group. PICE and RES's actions on RS generation were more effective than trolox, a reference compound; and RES-treated cells showed suppressions to $7.08 \%$ at $5 \mu \mathrm{M}$, $31.88 \%$ at $10 \mu \mathrm{M}$, and $46.88 \%$ at $50 \mu \mathrm{M}$, compared to the control. The present study also assessed the effects of PICE and RES on GSH and GSSG levels and the GSH/GSSG ratio. Table 3 shows that intracellular GSH levels in B16 cells were enhanced by PICE and RES, while GSSG levels were suppressed. Consequently, the GSH/GSSG ratio was increased by PICE and RES treatments, indicating an increased intracellular reducing power, which is expected to play an important role in the regulation of melanogenesis.

\section{DISCUSSION}

The inhibition of melanogenesis can be useful not only for cosmetic as skin-whitening purposes, but also for the treatment of abnormal pigmentation. In the present study, we provide the first evidence that PICE has a potent antime- 
lanogenic and antioxidative effects in B16 cells.

Figure 1 indicates the chemical structure of PICE compared with that of RES. RES is reported to have a tyrosinase inhibitory effect. ${ }^{22)}$ In current work, PICE and RES were compared for their tyrosinase inhibitory effect, with the result that PICE showed a more powerful tyrosinase inhibitory effect with the $\mathrm{IC}_{50}$ value of $1.53 \mu \mathrm{M}$, which was higher than RES at a value of $\mathrm{IC}_{50}=63.2 \mu \mathrm{M}$. To evaluate the relative efficacy of PICE compared to other tyrosinase inhibitors, its inhibitory effects were compared with the wellknown tyrosinase inhibitor, kojic acid, ${ }^{23)}$ showing that PICE was significantly stronger than kojic acid $\left(\mathrm{IC}_{50}=50.1 \mu \mathrm{M}\right)$.

The efficacy of inhibitory PICE may well be attributed to its phenolic structure with multiple hydroxyl groups. The structural significance of the phenol ring configuration in inhibitory actions was reported, as shown with hydroxystilbene compounds like oxyresveratrol for tyrosinase inhibitory action. ${ }^{12)}$ The stronger inhibitory action demonstrated by PICE may be related to the two hydroxyl groups located at the $C^{\prime}-3$ and $C^{\prime}-4$ position, an important structural factor for tyrosinase inhibition. ${ }^{24)}$

In our work, we examined and compared the inhibitory effect of PICE and RES on murine tyrosinase activity (Fig. 3 ) and found that PICE and RES effectively inhibited the tyrosinase activity compared to the $\alpha$-MSH-treated control group. We also examined the melanin content of cultured B16 cells in the presence of PICE and RES, and found that melanin content was effectively inhibited in a dose-dependent manner for each. In support of the mechanism by which PICE inhibits tyrosinase, we found that PICE and RES down-regulated the melanin synthesis. Our data verified our previous findings ${ }^{10)}$ and others ${ }^{25)}$ that the restraint of melanogenesis in B16 cells is characterized by the inhibition of tyrosinase.

The data on mushroom tyrosinase inhibition and inhibition of tyrosinase and melanin content in B16 cells indicate that PICE had more powerful effect than RES, as the more hydroxyl groups the stilbene have, the stronger the melanogenic inhibitory activity. These data are consistent with other findings ${ }^{11)}$ that the inhibitory potency of the hydroxystilbene compounds is markedly enhanced by the number of hydroxy groups on the phenolic ring. Because safety is a primary concern for skin lightening agents, the possible cytotoxicity of PICE was examined using B16 cells that were exposed to various concentrations of PICE. Figure 2 reveals that the cell viability was not compromised at any concentration tested compared with the untreated control.

To establish whether antimelanogenic activity is related to antioxidative properties of PICE, we quantitated RS generation and GSH and GSSG levels. As shown in Table 2, RS generation was inhibited by PICE in a concentration-dependent manner. PICE's effect may be related to not only the additional hydroxy group, but also contain ortho- $\left(3^{\prime}, 4^{\prime}-\right)$ dihydroxy groups that might play an important role in RS suppression. This result verifies previously reported data showing a potent scavenging effect of PICE. ${ }^{26)}$

Additionally, the effects of PICE on the GSH/GSSG ratio show that intracellular GSH levels in B16 cells were enhanced by PICE, while GSSG levels were down-regulated. Consequently, the GSH/GSSG ratio was increased by PICE, presenting an elevated intracellular reducing power that is expected to play a crucial role in the regulation of melanogenesis. Our data on increased GSH levels are in agreement with our previous report ${ }^{6}$ and correlated with those of another investigator who reported that GSH gives a novel state of interrupted melanogenesis in that melanization can't progress despite the complete formation of melanosome matrix structure and the deficiency of inhibition of cellular metabolism including protein glycosylation. ${ }^{27)}$ It is worth speculating on the possible explanation for the enhanced GSH level: A possibility of a direct action on GSH synthesizing enzymes or suppressing degradation of GSH by PICE.

Phenolic hydroxyl compound may show antioxidative activity because of its ability to donate an electron and/or chelate transition metals, such as copper or ferrous ions, thereby inhibit free radical reactions and diminish RS generation. $^{28)}$

One of the interesting findings of our study is that the potency of PICE is likely related to its duel efficacy on antimelanogenic and antioxidative activities. In summary, our study demonstrated that PICE inhibited tyrosinase activity and was able to decrease melanin content without showing any adverse effect on cell viability. Moreover, PICE showed antimelanogenic effects. These melanogenesis inhibitory activities paralleled the results of antioxidative activities. These stronger antimelanogenic and antioxidative actions of PICE are ascribed to its structural arrangement.

Acknowledgements The assistance of Ms. Corinne Price is greatly appreciated for the editing of this manuscript.

\section{REFERENCES}

1) Briganti S., Camera E., Picardo M., Pigment Cell Res., 16, 101-110 (2003).

2) Bohm M., Luger T. A., Hautarzt., 55, 436- 445 (2004).

3) Cooksey C. J., Garratt P. J. L., Land E. J., Pavel S., Ramsden C. A., Riley P. A., Smit N. P., J. Biol. Chem., 272, 226-235 (1997).

4) Perluigi M., De Marco F., Foppoli C., Coccia R., Blarzino C., Marcante M. L., Cini C., Biochem. Biophys. Res. Commun., 305, 250256 (2003).

5) Seo S. Y., Sharma V. K., Sharma N., J. Agric. Food Chem., 51, 28372853 (2003).

6) Benathan M., Alvero-Jackson H., Mooy A. M., Scaletta C., Frenk E., Melanoma Res., 2, 305-314 (1992).

7) No J. K., Kim Y. J., Lee J. S., Chung H. Y., Biol. Pharm. Bull., 29, $14-16$ (2006).

8) Roh J. S., Han J. Y., Kim J. H., Hwang J. K., Biol. Pharm. Bull., 27, 1976-1978 (2004).

9) No J. K., Kim M. S., Kim Y. J., Bae S. J., Choi J. S., Chung H. Y., Am. J. Chin. Med., 32, 1-7 (2004).

10) Kim Y. J., No J. K., Lee J. H., Chung H. Y., Biol. Pharm. Bull., 28, $323-327$ (2005).

11) Ohguchi K., Tanaka T., Kido T., Baba K., Iinuma M., Matsumoto K., Akao Y., Nozawa Y., Biochem. Biophys. Res. Commun., 307, 861863 (2003).

12) Kim Y. M., Yun J., Lee C. K., Lee H., Min K. R., Kim Y., J. Biol. Chem., 277, 16340-16344 (2002).

13) Sala G., Minutolo F., Macchia M., Sacchi N., Ghidoni R., Drugs Exp. Clin. Res., 29, 263-269 (2003).

14) Wenzel E., Somoza V., Mol. Nutr. Food Res., 49, 472-481 (2005).

15) Larrosa M., Tomas-Barberan F. A., Espin J. C., Eur. J. Nutr., 43, 275284 (2004).

16) No J. K., Soung D. Y., Kim Y. J., Shim K. H., Jun Y. S., Rhee S. H., Yokozawa T., Chung H. Y., Life Sci., 65, 241-246 (1999).

17) Bilodeau M. L., Greulich J. D., Hullinger R. L., Bertolotto C., Ballotti R., Andrisani O. M., Pigment Cell Res., 14, 328-336 (2001).

18) Tada H., Shiho O., Kuroshima K., Koyama M., Tsukamoto K. J., Im- 
munol. Methods, 93, 157-165 (1986).

19) Paraidathathu T., de Groot H., Kehrer J. P., Free Radic. Biol. Med., 13, 289-297 (1992).

20) Pandey A., Katiyar S. S., J. Enzyme Inhib., 11, 141-149 (1996).

21) Hall A. M., Croy V., Chan T., Ruff D., Kuczek T., Chang C., J. Nat. Prod., 59, 35-40 (1996).

22) Kim D. H., Kim J. H., Baek S. H., Seo J. H., Kho Y. H., Oh T. K., Lee C. H., Biotechnol. Bioeng., 87, 849-854 (2004).

23) Lim J. T., Dermatol. Surg., 25, 282-284 (1999).
24) Miyazawa M., Oshima T., Koshio K., Itsuzaki Y., Anzai J., J. Agric. Food Chem., 51, 6953-6956 (2003).

25) Mun Y. J., Lee S. W., Jeong H. W., Lee K. G., Kim J. H., Woo W. H., Biol. Pharm. Bull., 27, 806-809 (2004).

26) Cai Y. Z., Sun M., Jie Xing., Luo Q., Corke H., Life Sci., 78, 28722888 (2006).

27) Imokawa G., J. Invest. Dermatol., 93, 100-107 (1989).

28) Nerya O., Musa R., Khatib S., Tamir S., Vaya J., Phytochemistry, 65, 1389-1395 (2004). 